\title{
Sequence/structural analysis of xylem proteome emphasizes pathogenesis-related proteins, chitinases and $\beta-1,3-$ glucanases as key players in grapevine defense against Xylella fastidiosa
}

Sandeep Chakraborty, Rafael Nascimento, Paulo A. Zaini, Hossein Gouran, Basuthkar J. Rao, Luiz R. Goulart, Abhaya M. Dandekar

Background. Xylella fastidiosa, the causative agent of various plant diseases including Pierce's disease in the US, and Citrus Variegated Chlorosis in Brazil, remains a continual source of concern and economic losses, especially since almost all commercial varieties are sensitive to this Gammaproteobacteria. Differential expression of proteins in infected tissue is an established methodology to identify key elements involved in plant defense pathways. Methods. In the current work, we developed a methodology named CHURNER that emphasizes relevant protein functions from proteomic data, based on identification of proteins with similar structures that do not necessarily have sequence homology. Such clustering emphasizes protein functions which have multiple copies that are up/downregulated, and highlights similar proteins which are differentially regulated. As a working example we present proteomic data enumerating differentially expressed proteins in xylem sap from grapevines that were infected with $X$. fastidiosa. Results. Analysis of this data by CHURNER highlighted pathogenesis related PR-1 proteins, reinforcing this as the foremost protein function in xylem sap involved in the grapevine defense response to $X$. fastidiosa. $\beta$-1,3-glucanase, which has both anti-microbial and anti-fungal activities, is also up-regulated. Simultaneously, chitinases are found to be both up and down-regulated by CHURNER, and thus the net gain of this protein function loses its significance in the defense response. Discussion. We demonstrate how structural data can be incorporated in the pipeline of proteomic data analysis prior to making inferences on the importance of individual proteins to plant defense mechanisms. We expect CHURNER to be applicable to any proteomic data set. 
1 Sequence/structural analysis of xylem proteome emphasizes pathogenesis-related proteins,

2 chitinases and $\beta$-1,3-glucanases as key players in grapevine defense against Xylella

3 fastidiosa

4

5 Sandeep Chakraborty ${ }^{1, *}$, Rafael Nascimento ${ }^{1,2, *}$, Paulo A. Zaini ${ }^{2, *}$, Hossein Gouran ${ }^{1}$, Basuthkar J.

$6 \mathrm{Rao}^{3}$, Luiz R. Goulart ${ }^{2}$, Abhaya M. Dandekar ${ }^{1}$

7

8 1. Department of Plant Sciences, University of California, Davis, USA.

9 2. Institute of Genetics and Biochemistry, Federal University of Uberlândia, Campus Umuarama, 10 Uberlândia, Brazil.

11 3. Department of Biological Sciences, Tata Institute of Fundamental Research, Mumbai, India.

12

* These authors contributed equally to this work.

15 Corresponding author:

16 Abhaya M. Dandekar

17 Dept. of Plant Sciences - University of California

18 One Shields Avenue, Davis, CA 95616, USA

19 E-mail: amdandekar@ucdavis.edu 
22 Abstract

23 Background. Xylella fastidiosa, the causative agent of various plant diseases including Pierce's disease in the US, and Citrus Variegated Chlorosis in Brazil, remains a continual source of concern and economic losses, especially since almost all commercial varieties are sensitive to this Gammaproteobacteria. Differential expression of proteins in infected tissue is an established methodology to identify key elements involved in plant defense pathways.

Methods. In the current work, we developed a methodology named CHURNER that emphasizes relevant protein functions from proteomic data, based on identification of proteins with similar structures that do not necessarily have sequence homology. Such clustering emphasizes protein functions which have multiple copies that are up/down-regulated, and highlights similar proteins which are differentially regulated. As a working example we present proteomic data enumerating differentially expressed proteins in xylem sap from grapevines that were infected with $X$.

34 fastidiosa.

Results. Analysis of this data by CHURNER highlighted pathogenesis related PR-1 proteins, reinforcing this as the foremost protein function in xylem sap involved in the grapevine defense response to $X$. fastidiosa. $\beta$-1,3-glucanase, which has both anti-microbial and anti-fungal activities, is also up-regulated. Simultaneously, chitinases are found to be both up and downregulated by CHURNER, and thus the net gain of this protein function loses its significance in the defense response.

Discussion. We demonstrate how structural data can be incorporated in the pipeline of proteomic data analysis prior to making inferences on the importance of individual proteins to plant defense mechanisms. We expect CHURNER to be applicable to any proteomic data set. 


\section{Introduction}

Xylella fastidiosa ( $X$. fastidiosa) is a xylem-limited pathogen associated with diseases in many economically important plants, including Pierce's Disease of grape (PD) and Citrus Variegated Chlorosis (CVC) (Chatterjee et al. 2008). X. fastidiosa lives within the host's water-conducting xylem vessels, where it forms biofilms believed to be responsible for reduced hydraulic conductance caused by clogging of the vessels, and not increased cavitation and embolism of xylem elements (McElrone et al. 2003).

The xylem is composed mainly of lignified vessels that are used for the transportation of water, mineral nutrients and metabolites throughout the vascular system, and in long-distance signaling in response to biotic and abiotic stresses (de Bernonville et al. 2014). Xylem sap contains small molecular weight inorganic compounds, organic substances (Metzner et al. 2010), amino acids and proteins (Biles \& Abeles 1991). Recent improvements in genomic and proteomic technologies are accelerating the characterization of these proteins. The xylem sap proteome has been characterized in different plants, which has been shown to contain several protein families such as metabolic enzymes, stress-related proteins and signal transduction proteins (Buhtz et al. 2004; Dafoe \& Constabel 2009; Djordjevic et al. 2007; Kehr et al. 2005; Ligat et al. 2011; Rep et al. 2003; Zhang et al. 2015b). These include glycoside hydrolases, peroxidases, chitinases, lipid transfer proteins, proteases, lectins, pathogenesis-related proteins and cell wall structural proteins. The differential accumulation of proteins in xylem sap and apoplast fluid following pathogen infection has been investigated in some pathosystems, clearly indicating that protein composition changes during plant-pathogen interactions, both by the response of the host and by secreted effectors from the pathogen (Floerl et al. 2008; Gawehns et al. 2015; Houterman et al. 2007; Pu et al. 2016; Rep et al. 2002; Subramanian et al. 2009).

Vitis vinifera $\mathrm{cv}$. Chardonnay xylem sap protein composition was previously analyzed by twodimensional gel electrophoresis, which identified only ten proteins (Agüero et al. 2008). While the role played by xylem proteins in defense against biotic stress has been established in other plant species, the only information available about grapevine xylem sap proteins and their importance to plant response during $X$. fastidiosa pathogenesis came from the pioneering work and Yang and collaborators (2011) and a recent contribution by Katam et al. (2015). While the former showed that thaumatin-like and heat-shock proteins were significantly overexpressed in PD-resistant varieties of grape (Yang, et al. 2011), the latter found several uniquely expressed 
proteins ( $\beta$-1, 3-glucanases, 10-deacetyl baccatin III-10-O-acetyl transferase-like, COP9, and aspartyl protease nepenthesin precursor proteins) in PD-tolerant muscadine grape (Katam et al., 2015).The phenolic compounds altered during this plant-pathogen interaction has also been investigated (Wallis \& Chen 2012), expanding our understanding of the host molecular response to $X$. fastidiosa infection. Moreover, the comparison of the xylem sap proteome of PD-tolerant and PD-susceptible grapevine species revealed the presence of few proteins that might be directly involved with plant defense against $X$. fastidiosa (Basha et al. 2010). These studies however rely on protein sequence-based approaches for peptide mapping and identification (Altschul et al. 1997; Fenyo \& Beavis 2003), which limits exploring the wealth of information generated in proteomic analysis. Proteins with no sequence homology often possess similar enzymatic capabilities due to convergent evolution (Gherardini et al. 2007) and promiscuity (Chakraborty \& Rao 2012; Copley 2003; Jensen 1976); two well-studied phenomena analyzed by considering structural features. As structural data analysis can focus on several properties of target proteins rather than the one-dimensional alignments inherent to sequence-based methods, a structure-based data analysis approach is not well established for proteomics. We present a simple method for classifying protein sets using metrics derived from protein fold which can suggest putative functions to uncharacterized proteins by structural similarity. Our pipeline also performs a more localized perspective and analyzes specific active site residues to determine functional equivalence (Chakraborty et al. 2011; Kleywegt 1999). This approach was applied here to better understand the molecular basis of the interaction between this xylem-colonizing bacterium and grapevines, on data generated by comparing the composition of the xylem sap proteome of infected plants with that of healthy plants. Our analysis pipeline (CHURNER) was able to confirm previous studies cited above and identify novel proteins not previously detected or yet uncharacterized, and is freely available to be used with other proteomic data sets.

\section{Materials \& methods}

\section{Xylem sap collection and protein precipitation}

Xylem sap was collected from six 3-year-old grapevines (Vitis vinifera cv. 'Thompson Seedless') located at the University of California Davis (Armstrong field). Three of these plants were mechanically inoculated with Xylella fastidiosa Temecula1 12 months prior to sap collection. The presence of $X$. fastidios $a$ in the xylem sap of infected plants was confirmed using anti- $X$. 
107 fastidiosa antibodies in a Double Antibody Sandwich ELISA (Agdia, USA) following

108 manufacturer's instructions (Supplemental figure S1). Xylem sap (30-50 mL per plant) was

109

110

111

112

113

114

115

116

\section{7}

118

119

120

121

122

123

124

125

126

127

128

129

130

131

132

133

134

135

136

137

collected overnight in the second week of spring by drip of the cut stem of $X$. fastidiosa-infected and non-infected plants. To initiate sap collection, an apical segment of approximately $10 \mathrm{~cm}$ was cut from the stem and the vine terminal introduced into a collection tube sealed with parafilm. Xylem sap was lyophilized followed by protein precipitation using TCA/Acetone (Gorg et al. 2000). The pellets were resuspended in $300 \mu \mathrm{L}$ of PBS (pH 7.4) and total protein was quantified using BCA Protein Assay Kit (Thermo Fisher Scientific) following manufacturer's instructions for subsequent SDS-PAGE and LC-MS/MS analysis.

\section{Protein preparation, mass spectrometry analysis and NMR imaging}

Proteins were precipitated using ProteoExtract ${ }^{\mathrm{TM}}$ Protein Precipitation kit (Calbiochem) followed by dehydration overnight in a sterile fume hood. The protein pellet was then resuspended in 50 $\mathrm{mM}$ AmBic (pH 8.0) and $100 \mu \mathrm{g}$ subjected to an in-solution tryptic digestion. The digested peptides were analyzed using a QExactive mass spectrometer (Thermo Fisher Scientific) coupled with an Easy-LC (Thermo Fisher Scientific) and a nanospray ionization source. One microgram of digested peptides were loaded onto a trap (100 micron, $\left.\mathrm{C} 18100^{\circ} \mathrm{A} 5 \mathrm{U}\right)$ and desalted online before separation using a reverse phased column ( 75 micron, $\left.\mathrm{C} 18200^{\circ} \mathrm{A} 3 \mathrm{U}\right)$. The gradient duration for separation of peptides was 60 minutes using $0.1 \%$ formic acid and $100 \%$ acetonitrile as solvents A and B, respectively. Raw data was analyzed using X!Tandem (Fenyo \& Beavis 2003) and visualized using Scaffold version 4.4.1 (Proteome Software, OR). Samples were searched against UniProt databases appended with the cRAP database, which recognizes common laboratory contaminants. Reverse decoy databases were also applied to the database prior to the X!Tandem searches. Peptide identifications were accepted if they could be established at greater than $95 \%$ probability by the Peptide Prophet algorithm (Keller et al. 2002; Nesvizhskii et al. 2003) with Scaffold delta-mass correction. Protein identifications were accepted if they could be established at greater than $99 \%$ probability and contained at least 2 identified peptides (see supplemental file S1 for raw data of identified proteins. All supplemental material is available at https://drive.google.com/drive/folders/0BxTKjdWklOUbdmlpdXZQdG00bWc). Proteins that contained similar peptides and could not be differentiated based on MS/MS analysis alone were 
138 grouped to satisfy the principles of parsimony. For relative protein quantification of xylem sap

139 from infected and non-infected plants, the QSpec statistical framework (Version

140

141

142

143

144

145

146

147

148

149

150

151

152

153

154

155

156

157

158

159

160

161

162

163

164

165

166

167

168

2,http://sourceforge.net/pro jects/qspec/) was used to assign significance to differentially regulated proteins, using a Bayes factor $>10$ (Choi et al. 2008).

Nuclear magnetic resonance imaging $\left({ }^{1} \mathrm{H}-\mathrm{MRI}\right)$ was done in an Avance 400 spectrometer equipped with Bruker DRX console microimaging accessory according to (Dandekar et al. 2012). Stem transverse sections of all non-infected and infected plants were collected between internodes located at the top (apical), middle and bottom of the central stem (three cuts per plant) and subjected to MRI. Figure 2 shows representative results.

\section{Downstream In silico methods}

We have written custom programs to automate the extraction of protein sequences, their annotation through the BLAST command line (Camacho 2008), obtaining homologous PDB structures, and getting pairwise structural homology (Konc \& Janezic 2010) from proteome data mined with Prophet/Scaffold program (Keller et al. 2002) (see example dataset in supplemental file S1). These programs were integrated in the CHURNER pipeline using freely available BioPerl (Stajich et al. 2002) modules and Emboss (Rice et al. 2000) tools (additional documentation and scripts available as supplemental files S2 and S3). As manual steps, we performed gene ontology of the differentially expressed proteins using the statistical overrepresentation test from the PANTHER protein classification system (Mi et al. 2013), and FATCAT (Ye \& Godzik 2004) to supervise and validate the structural homology. All protein structures were rendered by the PyMol Molecular Graphics System, version 1.7.4 Schrödinger, LLC (http://www.pymol.org/). Detection of putative signal peptides and target sub-cellular locations of proteins were done with SignalP 3.0 (Bendtsen et al. 2004) and TargetP 1.1 (Emanuelsson et al. 2007), respectively. Protein sequences used in sequence and structural alignments were devoid of signal sequences to better represent mature proteins. Congruence of specific active site residues to determine functional equivalence between proteins was performed with CLASP (Chakraborty et al. 2011). Adaptive Poisson-Boltzmann Solver (APBS) and PDB2PQR packages were used to calculate the electrostatic potentials of all the atoms in the protein (Baker et al. 2001; Dolinsky et al. 2004). The APBS parameters were set as described previously in (Chakraborty et al. 2011). APBS writes out the electrostatic potential in 
169 dimensionless units of $\mathrm{kT} / \mathrm{e}$ where $\mathrm{k}$ is Boltzmann's constant, $\mathrm{T}$ is the temperature in $\mathrm{K}$ and $\mathrm{e}$ is

170 the charge of an electron, used to calculate the pairwise potential differences.

171

172

173

174

175

\section{Results \& Discussion}

\section{The CHURNER workflow for proteome analysis}

CHURNER implements tandem analysis of sequence and structure of proteins to highlight potential functional similarities not obvious from simple sequence alignments. It uses simple Perl scripts to obtain the pairwise sequence and structural homology scores from BLAST and ProBiS, respectively (Figure 1). The structural homology is then checked with FATCAT by the FCTSIG significance test (Ye \& Godzik 2004). We used these well established methods with different algorithms to detect structural similarity. This helps us corroborate the results between them (PZ scores). FATCAT treats the protein as flexible, allowing twists in the reference protein (akin to a real protein) and minimizes the number of rigid-body movements for the best structural alignment. ProBiS relies on common surface structural patches rather than global conservation in finding structural similarity, with the reasoning that the surface residues are more critical since they determine ligand or protein-protein interactions. The source code, working directory and a README script for the current example is available as supplemental material (see Methods). As a working example we used proteins identified by LC-MS/MS from xylem sap of grapevines infected with $X$. fastidiosa as described below. By using CHURNER we were able to highlight the Pathogenesis-Related proteins (PR-1) as the main proteins of grapevine defense against $X$. fastidiosa to be secreted in xylem sap and also to unravel structural similarity between $\beta$-Dglucan exo-hydrolase and chitinases, which has no known reference in existing literature. To the best of our knowledge, this is the first attempt to analyze proteomic data for differentially expressed proteins based on structural features. A walkthrough of the steps implemented by CHURNER will be demonstrated next.

\section{Our working example: xylem sap proteins identification by LC-MS/MS}

In this study, proteins from xylem sap of $X$. fastidiosa-infected and non-infected grapevines were lyophilized, precipitated by TCA/acetone and analyzed by SDS-PAGE (Supplemental Figure S2). A total of 91 proteins (Table 1) were identified herein by LC-MS/MS with at least two peptides sequenced per protein. SignalP and TargetP were used to predict the presence of signal 
200 peptides and sub-cellular localization, respectively, in all protein sequences. Signal peptides were

201 found in 70 proteins $(77 \%)$ of which 67 were predicted to be secreted while the others are

202 directed towards an undetermined sub-cellular location.

203

\section{Differentially expressed proteins in xylem sap of infected plants}

Previous reports investigating differentially expressed transcripts and proteins in xylem sap of $X$. fastidiosa-infected plants have provided a wealth of information regarding the plant responses to infection, both in grapevines (Katam et al. 2015; Lin et al. 2007; Yang et al. 2011) and citrus (Rodrigues et al. 2013). These include PR proteins, $\beta$-1,3-glucanases, LRR-RLKs and chitinases listed in Table 1. From all proteins detected in xylem sap, those with significant fold changes as indicated by the Prophet/Scaffold program (See supplemental file S1 with protein quantification data and file S4 for multifasta protein sequences) were re-annotated using the BLAST command line interface (Camacho 2008). Twelve of those for which a predicted structure could be assigned in the Protein Data Bank were further analyzed in the CHURNER pipeline (Table 2). Despite some UniProt IDs not having the proper functional annotation, as for example protein UID: F6HBN7, which is not annotated as a pathogenesis-related protein in http://www.uniprot.org/uniprot/F6HBN7, CHURNER uses UniProt IDs as protein identifiers, as it is easily streamlined with other applications such as the PANTHER gene ontology analysis server. The PANTHER overrepresentation test uses the most updated gene ontology database released, and has the option to use Bonferroni correction for multiple testing, which did not alter our results. It also has a wide range of reference genomes to be queried with the user list. Nine of twelve of our differentially expressed proteins could be mapped to ontology terms by PANTHER. The molecular functions with significant overrepresentation were chitinase and glycosyl hydrolase activities (GO:0004568, and GO:0016798, respectively. See complete GO analysis in supplemental file S5). Accordingly, the biological processes overrepresented were catabolism of glucosamines (GO:1901072), chitin (GO:0006032), amino glycans (GO:0006026) and amino sugars (GO:0046348). Interestingly, identification of differentially expressed proteins demonstrated that NtPRp27, which is found in the xylem exudate of non-infected grapevines (Agüero et al. 2008), and is a known pathogenesis-related protein (Okushima et al. 2000) was not over-expressed upon $X$. fastidiosa infection. Comparably, two LRR-RLK (Ciclev10004108m and Ciclev10014130m) found to be up-regulated in Ponkan mandarin infected with $X$. fastidiosa 
231 (Rodrigues et al. 2013), were not affected in our data, despite LRR-RLKs being detected in our 232 proteomic analysis (Table 1). Plant receptor-like kinases (RLKs) are a large gene family $(\sim 600$ members in Arabidopsis) (Shiu \& Bleecker 2001), consisting of an accelerated evolutionary domain implicated in signal reception through leucine-rich repeat (LRRs) (Afzal et al. 2008). Resistance (R) genes have evolved to counter pathogens that bypass the pathogen-associated molecular patterns (PAMP) mechanism in plants (Nicaise et al. 2009). Most R genes encode proteins comprising of a nucleotide-binding site (NBS) and leucine-rich repeats (LRRs), and recognize and neutralize specialized pathogen avirulence (Avr) proteins, providing plants with resistance (Borhan et al. 2004; Chakraborty et al. 2016; Ernst et al. 2002; Hayashi et al. 2010; Zhang et al. 2010).

\section{Up-regulated proteins}

The up-regulated protein F6HLL8 listed in Table 2 is a $\beta$-1,3-glucanase (GNS), a wellestablished pathogenesis related protein (Balasubramanian et al. 2012; Shinshi et al. 1988). GNS has strong anti-microbial (Xie et al. 2015) and anti-fungal activity (Su et al. 2013). Expectedly, it is a target of pathogen toxins in the ensuing evolutionary battle (Sanchez-Rangel et al. 2012; Zhang et al. 2015b). GNS, along with chitinase, has been shown to inhibit fungal growth (Mauch et al. 1988; Sela-Buurlage et al. 1993). The presence of two up-regulated chitinases (UIDs: A5BK69, D7T548) induced by $X$. fastidiosa demonstrates that this defense response is similar during both bacterial and fungal attack. Both these chitinases belong to the GH18 sub-family of chitinases (Funkhouser \& Aronson 2007). Another up-regulated protein is an expansin-like B1 enzyme (UID: A5C594), also a carbohydrate-binding protein involved in cell-wall loosening and restructuring (Zhang et al. 2014). Homologs have previously been link to abiotic stress responses (Han et al. 2014; Nanjo et al. 2013). Two other proteins (UID: F6HBN7, A5BNW5) are the wellestablished defense PR-1 pathogenesis related proteins (Sudisha et al. 2012). Several functions have previously been attributed to PR1 including, antiviral activity in tobacco (Antoniw \& White 1980) and anti-herbivory activity in maize (Zhang et al. 2015a). Additional activities suggest protease-mediated programmed cell death pathways in plants (Lu et al. 2013), a symptom commonly seen in leaves of Pierce's diseased grapevines. A lipid-transfer protein of the DIR1 type (UID: D7TML8) also ranks among the up-regulated proteins, suggesting a systemic defense response being activated, as previously seen in Arabidopsis (Champigny et al. 2013). A blue 
262 copper protein-like was also identified as up-regulated. This redox protein family is part of a widespread but yet poorly characterized defense mechanism in plants and/or lignin formation (Cao et al. 2015; Nersissian et al. 1998). It is interesting to note an abundance of cell-wall modification enzymes in xylem sap from infected plants, as this corroborates previous observations in other pathosystems such as Xanthomonas oryzae infection of rice (Hilaire et al. 2001), among others (van Loon et al. 2006). Since vines infected with $X$. fastidiosa commonly display an increase in stem diameter, we verified if this reflected in an increase of secondary wall deposition by nuclear magnetic resonance imaging (Figure 2). Indeed the MRI showed an increase in dense material (colored in light shades in Figure 2) in infected plant stems, including those used for xylem sap collection. Recently it has also been demonstrated that citrus infected with $X$. fastidiosa display a thickening of secondary cell-walls (Niza et al. 2015).

\section{Down-regulated proteins}

As mentioned previously the GH19 sub-family chitinase (UID: F6GZC4) is down-regulated. A similar suppression of a chitinase gene in response to mycorrhizal fungus Glomus intraradices infection of tobacco roots has been noted previously (David et al. 1998). The GH19 sub-family has members that are sugar-binding proteins but without catalytic activity (Martinez-Caballero et al. 2014). Further experimentation is necessary to verify whether this is the case in Vitis vinifera, as it can be part of the cell-wall remodeling in response to the pathogen, as previously suggested by other works (Lin et al. 2007; Rodrigues et al. 2013). A thaumatin-like protein (TLP) (UID: A5AWT7) is also found to be down-regulated upon $X$. fastidiosa infection. TLP's are found in most eukaryotes, and involved in host defense and several developmental processes (Liu et al. 2010). While TLP over expression has been shown to enhance resistance to Alternaria alternata in tobacco (Safavi et al. 2012), these proteins can also be down-regulated in some cases, as shown in the compilation of transcriptomes of poplar leaf rust infections (Petre et al. 2011). A $\beta$ D-xilosidase 4 ortholog (UID: F6I6R4) was also down-regulated in infected vines, again reinforcing the drastic effect on cell-wall remodeling enzymes upon pathogen infection. The other down-regulated protein in Table 2 is a LTP similar to YLS3 (yellow-leaf-specific) which is a marker of leaf senescence, being induced in earlier stages and repressed in later stages in Arabidopsis (Yoshida et al. 2001). 


\section{Sequence homology}

294 Although in our data set only twelve proteins were selected for further analysis through

CHURNER, there might be cases when larger data sets render a manual inspection of homologous proteins difficult. Even in the current case, it is difficult to identify D7SLG6 as a lipid transfer protein (LTP) from the BLAST automated annotation (Table 2, value marked in italic). Thus, as the next step in CHURNER, we implemented a pairwise BLAST of all mature proteins (devoid of signal sequences). Table 3 shows the pairwise sequence homology with an Evalue cutoff of 0.005 . There are several interesting aspects that emerge from this comparison. As expected, the two PR-1 proteins are found to be significantly homologous. The 'YLS3-like' protein (UID: D7SLG6) is found to be quite similar to another LTP (UID: D7TML8). Furthermore, we observe sequence homology between chitinases and expansin (E-value $=4 \mathrm{e}-$ $04)$, and much less between chitinases and PR-1 proteins $(E-v a l u e=0.002)$. Interestingly, these similarities are greater than that between the two known chitinases from sub-family GH18 (Evalue $=0.003)$. This raises the interesting question whether these proteins (chitinases/expansin/PR-1) have promiscuous functions (Chakraborty \& Rao 2012; Khersonsky structural annotation as the next step in CHURNER. protein sequences, thus providing a more rational alternative to identify proteins with similar functions. Since the structure of a protein is intrinsically related to its function, we implemented

\section{Structural annotation}

CHURNER implements an automated search for homologous proteins with known PDB structures (Table 2). As expected, proteins with high similarity and alignment at the sequence level map to the same PDB structure, such as the PR-1 proteins (PDBid: 1CFE, PR-14a protein). Interestingly, this protein was identified as a possible replacement of the human neutrophil elastase component of the chimeric protein (Chakraborty 2012; Chakraborty et al. 2013) that provided enhanced grapevine resistance to $X$. fastidiosa (Dandekar et al. 2012). Moreover, apart from the LTP (UID: D7SLG6, E-value $=0.017$ ), all matches are very significant to their PDB closest model.

\section{Structural homology}


324 Using the structures corresponding to the identified proteins, we detected similarities that might

325 have escaped detection in the sequence homology search. Table 4 shows the most significant pairwise structural comparison of the structures (excluding the PR-1 proteins which have the same PDB structure) computed using ProBiS (Konc \& Janezic 2010). We subsequently verified the alignment significance using the FATCAT server (Ye \& Godzik 2004). The ProBiS Z-score (PZ in Table 4) are standardized alignment scores (Konc \& Janezic 2010) which provide statistical and structural significance of local structural alignments. Z-scores $>2$ are considered highly significant (PDBs: $2 \mathrm{RKN} / 1 \mathrm{FK} 0$ and $1 \mathrm{HVQ} / 3 \mathrm{AQU}$ ), although a Z-score of 1.6 is also significant (PDBs: 3AQU/1EX1), as confirmed by FATCAT (which looks at the global structure). The LTPs (with a sequence homology E-value $=1 \mathrm{e}-06$ ) are structurally homologous, as expected (Figure 3A). Noteworthy, the chitinases from the GH18 family with a low sequence homology $(E-v a l u e=0.003)$ are structurally homologous (Figure 3B). Finally, in spite of a much lower sequence homology (E-value $=0.44$ ), the chitinase (UID: D7T548) and the $\beta$-D-glucan exohydrolase (UID: F6I6R4) are structurally homologous (Figure 3C). These observations highlight the necessity of structural comparison in annotating and grouping proteins based on functionality in proteomic analysis, and points to alternative protein functions that can be tested in subsequent studies.

Environmental stimuli (Yang et al. 2012), pathogens (Moy et al. 2004) or disease (Ng et al. 2009) induce differential expression of specific genes. Rapid technological advances have helped us identify these genes, and define their roles in defense or pathogenesis. While quantifying transcripts through high-throughput sequencing techniques have revolutionized these efforts (Wang et al. 2009), the correlation between transcriptional and protein abundance remains suspect (Gygi et al. 1999) due to the complexity of the regulatory factors modulating translation (Zhu et al. 2012). Thus, identifying proteins through techniques like mass spectrometry (Witzel et al. 2009), and measuring their relative amounts (Hu et al. 2015), provides a true picture of the genes involved in pathogenesis and defense response, rather than measuring their RNA abundance (Moy et al. 2004). Nevertheless, the value of transcriptomic analysis should not be underestimated as it has proved to be an effective approach to discover genes responsive to infection, as exemplified by sequencing of expressed sequence tags from $X$. fastidiosa-infected grapevines (Lin et al. 2007) and citrus (Rodrigues et al. 2013). 
354 Here we showed that several proteins (pathogenesis-related PR-1, chitinases and $\beta-1,3-$

355 glucanases) are differentially expressed in the xylem sap of grapevine infected with $X$. fastidiosa, using LC-MS/MS with at least two peptides sequenced per protein, confirming findings of previous investigations. These proteins are recognized as key players in the plant response against pathogen infection, as exemplified by sugarcane infected by Sporisorium scitamineum (Su et al. 2013) and other pathosystems reviewed in (Sudisha et al. 2012). Interestingly, we observed that there are two chitinases which are regulated differently (UniProt IDs F6GZC4 and D7T548, Table 4). Chitinases degrade chitin, a component of fungal cell walls (David et al. 1998). This observation diminishes the importance of chitinase as a generic defense agent against $X$. fastidiosa. It is also possible that the plant response to the infecting bacterial agent is indifferent to the expression levels of these anti-fungal chitinases, for which we warrant further studies. The pathogenic state can also be characterized by differentially expressed genes within $X$. fastidiosa itself (Shi et al. 2010). Consequently, the analysis of differentially expressed genes and proteins should consider functionally related proteins as a single entity, and not just the expression levels of single genes or proteins. CHURNER allows for such selection based on both sequence and structural homology, as often, the best match for a sequence has an incomplete annotation. Subsequently, structural homology can identify functional relationship among sequences with little sequence homology. For example, the two chitinase homologs have low pairwise sequence homology $(E-v a l u e=0.003)$. However, their significant homologous counterparts in the PDB database are PDBid: 4DWXA (Secale cereale, rye) and PDBid: 3AQU (Arabidopsis thaliana) have significant structural homology, as computed using ProBiS (Konc \& Janezic 2010) and FATCAT (Ye \& Godzik 2004).

\section{Corroborating the promiscuity of the chitinase and $\beta$-D-glucan exohydrolase by active site} structural homology

The $\beta$-D-glucan exohydrolase (PDBid: 1EX1) is critical for hydrolysis of cell walls, containing high levels of 1,3- $\beta$-D-glucans, during wall degradation in germinated grain and during wall loosening in elongating coleoptiles (Varghese et al. 1999). Interestingly, the fungal wall is composed of chitin, 1,3- $\beta$ - and 1,6- $\beta$-glucan, mannan and proteins (Adams 2004). Thus, the upregulation of both chitinases and $\beta$-D-glucan exohydrolases is possibly an anti-fungal defense response that has been triggered by $X$. fastidiosa. We have seen that the chitinase and the $\beta$-D- 
385 glucan exohydrolase have no sequence homology (Table 3), but partial structural homology 386 (Table 4). A detailed analysis of their catalytic residues further strengthens credence of their functional similarity. For $\beta$-D-glucan exohydrolase, Asp285 and Glu491 are involved in catalysis (Varghese et al. 1999). In chitinases, the Asp114 and Glu116 are a part of the conserved motif (DXXDXDXE) (Hamid et al. 2013). The active site residues of these proteins demonstrate significant spatial (Figure 4) and electrostatic congruence (Table 5) determined using CLASP. The absence of sequence linearity indicates that this homology arose from convergent evolution. Remarkably, based on the catalytic triad of the barley $\beta$-D-glucan exohydrolase (PDBid: 1EX1A) provided to CLASP, it was able to pick up the catalytic triad from the Arabidopsis chitinase (PDBid: 3AQU) despite the lack of sequence homology. We later realized this prediction was correct consulting the work from Ohnuma and collaborators on the crystallographic studies of this type V chitinase (2011).

\section{Conclusions}

A robust proteomic methodology was used to identify novel protein fragments in addition to the proteins identified previously using two-dimensional gel electrophoresis followed by sequencing of protein spots in non-infected xylem exudates collected from Vitis vinifera $\mathrm{cv}$. Chardonnay vines (Agüero et al. 2008), and mass spectrometric analysis of $X$. fastidiosa-infected grapevines (Katam et al. 2015; Yang et al. 2011). Thus, here we link the expression pattern of well-studied proteins in grapevines to the pathogen perception response, and present a methodology for assessing their significance by taking into account both their sequence and structural information. Although our data came from a single round of infection containing three plants (and three non-infected control plants), our findings are consistent among the different samples and to previous proteomic studies of $X$. fastidiosa infected grapevines. In conclusion, CHURNER enhances our ability to find functionally-relevant protein candidates that have little or no sequence similarity, and thus would be considered as separate components of a data set. The name "CHURNER" was inspired in the mixing tool used to reach the "cream". We intend to offer a tool to enable for detection of "cream" protein functions, not obvious from simple amino acid sequence alignments. The reduced data set employed in this work was used as a proof of 414 concept, and we encourage readers to use complex data sets with thousands of proteins to find 415 many putative functional relations among proteins that are yet unexplored. 


\section{Acknowledgements}

418

We thank James Mitch Elmore for helpful suggestions in proteomic analysis.

\section{References}

Adams DJ. 2004. Fungal cell wall chitinases and glucanases. Microbiology 150:2029-2035. 10.1099/mic.0.26980-0 150/7/2029 [pii]

Afzal AJ, Wood AJ, and Lightfoot DA. 2008. Plant receptor-like serine threonine kinases: roles in signaling and plant defense. Mol Plant Microbe Interact 21:507-517. 10.1094/MPMI-21-5-0507

Agüero CB, Thorne ET, Ibáñez AM, Gubler WD, and Dandekar AM. 2008. Xylem Sap Proteins from Vitis vinifera L. Chardonnay. American Journal of Enology and Viticulture 59:306-311.

Altschul SF, Madden TL, Schaffer AA, Zhang J, Zhang Z, Miller W, and Lipman DJ. 1997. Gapped BLAST and PSI-BLAST: a new generation of protein database search programs. Nucleic Acids Res 25:3389-3402. gka562 [pii]

Antoniw JF, and White RF. 1980. The Effects of Aspirin and Polyacrylic Acid on Soluble Leaf Proteins and Resistance to Virus Infection in Five Cultivars of Tobacco. Journal of Phytopathology 98:331-341.

Baker NA, Sept D, Joseph S, Holst MJ, and McCammon JA. 2001. Electrostatics of nanosystems: application to microtubules and the ribosome. Proc Natl Acad Sci U S A 98:10037-10041. 10.1073/pnas.181342398

181342398 [pii]

Balasubramanian V, Vashisht D, Cletus J, and Sakthivel N. 2012. Plant beta-1,3-glucanases: their biological functions and transgenic expression against phytopathogenic fungi. Biotechnol Lett 34:1983-1990. $10.1007 / \mathrm{s} 10529-012-1012-6$

Basha SM, Mazhar H, and Vasanthaiah HK. 2010. Proteomics approach to identify unique xylem sap proteins in Pierce's disease-tolerant Vitis species. Appl Biochem Biotechnol 160:932-944. 10.1007/s12010-009-8620-1

Bendtsen JD, Nielsen H, von Heijne G, and Brunak S. 2004. Improved prediction of signal peptides: SignalP 3.0. $J$ Mol Biol 340:783-795. 10.1016/j.jmb.2004.05.028

S0022283604005972 [pii]

Biles CL, and Abeles FB. 1991. Xylem sap proteins. Plant Physiol 96:597-601.

Borhan MH, Holub EB, Beynon JL, Rozwadowski K, and Rimmer SR. 2004. The arabidopsis TIR-NB-LRR gene RAC1 confers resistance to Albugo candida (white rust) and is dependent on EDS1 but not PAD4. Mol Plant Microbe Interact 17:711-719. 10.1094/MPMI.2004.17.7.711

Camacho C. 2008. BLAST ${ }^{\circledR}$ Command Line Applications User Manual [Internet]. Bethesda (MD): National Center for Biotechnology Information (US); 2008-. Available from: . Available at http://www.ncbi.nlm.nih.gov/books/NBK279690/.

Cao J, Li X, Lv Y, and Ding L. 2015. Comparative analysis of the phytocyanin gene family in 10 plant species: a focus on Zea mays. Front Plant Sci 6:515. 10.3389/fpls.2015.00515

Chakraborty S. 2012. An automated flow for directed evolution based on detection of promiscuous scaffolds using spatial and electrostatic properties of catalytic residues. PLoS One 7:e40408. 10.1371/journal.pone. 0040408

PONE-D-12-13078 [pii]

Chakraborty S, Britton M, Martinez-Garcia PJ, and Dandekar AM. 2016. Deep RNA-Seq profile reveals biodiversity, plant-microbe interactions and a large family of NBS-LRR resistance genes in walnut (Juglans regia) tissues. AMB Express 6:12. 10.1186/s13568-016-0182-3

10.1186/s13568-016-0182-3 [pii]

Chakraborty S, Minda R, Salaye L, Bhattacharjee SK, and Rao BJ. 2011. Active site detection by spatial conformity and electrostatic analysis--unravelling a proteolytic function in shrimp alkaline phosphatase. PLoS One 6:e28470. 10.1371/journal.pone.0028470

PONE-D-11-14548 [pii]

Chakraborty S, Minda R, Salaye L, Dandekar AM, Bhattacharjee SK, and Rao BJ. 2013. Promiscuity-based enzyme selection for rational directed evolution experiments. Methods Mol Biol 978:205-216. 10.1007/978-162703-293-3_15 
Chakraborty S, and Rao BJ. 2012. A measure of the promiscuity of proteins and characteristics of residues in the vicinity of the catalytic site that regulate promiscuity. PLoS One 7:e32011. 10.1371/journal.pone.0032011

PONE-D-11-20732 [pii]

Champigny MJ, Isaacs M, Carella P, Faubert J, Fobert PR, and Cameron RK. 2013. Long distance movement of DIR1 and investigation of the role of DIR1-like during systemic acquired resistance in Arabidopsis. Front Plant Sci 4:230. 10.3389/fpls.2013.00230

Chatterjee S, Almeida RP, and Lindow S. 2008. Living in two worlds: the plant and insect lifestyles of Xylella fastidiosa. Annu Rev Phytopathol 46:243-271. 10.1146/annurev.phyto.45.062806.094342

Choi H, Fermin D, and Nesvizhskii AI. 2008. Significance analysis of spectral count data in label-free shotgun proteomics. Mol Cell Proteomics 7:2373-2385. 10.1074/mcp.M800203-MCP200

Copley SD. 2003. Enzymes with extra talents: moonlighting functions and catalytic promiscuity. Curr Opin Chem Biol 7:265-272. S1367593103000322 [pii]

Dandekar AM, Gouran H, Ibanez AM, Uratsu SL, Aguero CB, McFarland S, Borhani Y, Feldstein PA, Bruening G, Nascimento R, Goulart LR, Pardington PE, Chaudhary A, Norvell M, Civerolo E, and Gupta G. 2012. An engineered innate immune defense protects grapevines from Pierce disease. Proc Natl Acad Sci USA 109:3721-3725. 10.1073/pnas.1116027109

David R, Itzhaki H, Ginzberg I, Gafni Y, Galili G, and Kapulnik Y. 1998. Suppression of tobacco basic chitinase gene expression in response to colonization by the arbuscular mycorrhizal fungus Glomus intraradices. Mol Plant Microbe Interact 11:489-497. 10.1094/MPMI.1998.11.6.489

de Bernonville TD, Albenne C, Arlat M, Hoffmann L, Lauber L, and Jamet E. 2014. Xylem sap proteomics. Methods Mol Biol 1072:391-405.

Dolinsky TJ, Nielsen JE, McCammon JA, and Baker NA. 2004. PDB2PQR: an automated pipeline for the setup of Poisson-Boltzmann electrostatics calculations. Nucleic Acids Res 32:W665-667. 10.1093/nar/gkh381

32/suppl_2/W665 [pii]

Emanuelsson O, Brunak S, von Heijne G, and Nielsen H. 2007. Locating proteins in the cell using TargetP, SignalP and related tools. Nat Protoc 2:953-971. nprot.2007.131 [pii]

10.1038/nprot.2007.131

Ernst K, Kumar A, Kriseleit D, Kloos DU, Phillips MS, and Ganal MW. 2002. The broad-spectrum potato cyst nematode resistance gene (Hero) from tomato is the only member of a large gene family of NBS-LRR genes with an unusual amino acid repeat in the LRR region. Plant J 31:127-136. 1341 [pii]

Fenyo D, and Beavis RC. 2003. A method for assessing the statistical significance of mass spectrometry-based protein identifications using general scoring schemes. Anal Chem 75:768-774.

Floerl S, Druebert C, Majcherczyk A, Karlovsky P, Kues U, and Polle A. 2008. Defence reactions in the apoplastic proteome of oilseed rape (Brassica napus var. napus) attenuate Verticillium longisporum growth but not disease symptoms. BMC Plant Biol 8:129. 1471-2229-8-129 [pii]

10.1186/1471-2229-8-129

Funkhouser JD, and Aronson NN, Jr. 2007. Chitinase family GH18: evolutionary insights from the genomic history of a diverse protein family. BMC Evol Biol 7:96. 10.1186/1471-2148-7-96

Gawehns F, Ma L, Bruning O, Houterman PM, Boeren S, Cornelissen BJ, Rep M, and Takken FL. 2015. The effector repertoire of Fusarium oxysporum determines the tomato xylem proteome composition following infection. Front Plant Sci 6:967. 10.3389/fpls.2015.00967

Gherardini PF, Wass MN, Helmer-Citterich M, and Sternberg MJ. 2007. Convergent evolution of enzyme active sites is not a rare phenomenon. J Mol Biol 372:817-845. S0022-2836(07)00812-1 [pii]

10.1016/j.jmb.2007.06.017

Gorg A, Obermaier C, Boguth G, Harder A, Scheibe B, Wildgruber R, and Weiss W. 2000. The current state of twodimensional electrophoresis with immobilized $\mathrm{pH}$ gradients. Electrophoresis 21:1037-1053. 10.1002/(SICI)1522-2683(20000401)21:6<1037::AID-ELPS1037>3.0.CO;2-V [pii]

10.1002/(SICI)1522-2683(20000401)21:6<1037::AID-ELPS1037>3.0.CO;2-V

Gygi SP, Rochon Y, Franza BR, and Aebersold R. 1999. Correlation between protein and mRNA abundance in yeast. Mol Cell Biol 19:1720-1730.

Hamid R, Khan MA, Ahmad M, Ahmad MM, Abdin MZ, Musarrat J, and Javed S. 2013. Chitinases: An update. J Pharm Bioallied Sci 5:21-29. 10.4103/0975-7406.106559

JPBS-5-21 [pii]

Han Y, Chen Y, Yin S, Zhang M, and Wang W. 2014. Over-expression of TaEXPB23, a wheat expansin gene, improves oxidative stress tolerance in transgenic tobacco plants. J Plant Physiol 173C:62-71. S01761617(14)00264-8 [pii] 
10.1016/j.jplph.2014.09.007

Hayashi N, Inoue H, Kato T, Funao T, Shirota M, Shimizu T, Kanamori H, Yamane H, Hayano-Saito Y, Matsumoto T, Yano M, and Takatsuji H. 2010. Durable panicle blast-resistance gene Pb1 encodes an atypical CCNBS-LRR protein and was generated by acquiring a promoter through local genome duplication. Plant $J$ 64:498-510. 10.1111/j.1365-313X.2010.04348.x

Hilaire E, Young SA, Willard LH, McGee JD, Sweat T, Chittoor JM, Guikema JA, and Leach JE. 2001. Vascular defense responses in rice: peroxidase accumulation in xylem parenchyma cells and xylem wall thickening. Mol Plant Microbe Interact 14:1411-1419. 10.1094/MPMI.2001.14.12.1411

Houterman PM, Speijer D, Dekker HL, CG DEK, Cornelissen BJ, and Rep M. 2007. The mixed xylem sap proteome of Fusarium oxysporum-infected tomato plants. Mol Plant Pathol 8:215-221. MPP384 [pii]

10.1111/j.1364-3703.2007.00384.x

Hu J, Rampitsch C, and Bykova NV. 2015. Advances in plant proteomics toward improvement of crop productivity and stress resistancex. Front Plant Sci 6:209. 10.3389/fpls.2015.00209

Jensen RA. 1976. Enzyme recruitment in evolution of new function. Annu Rev Microbiol 30:409-425. 10.1146/annurev.mi.30.100176.002205

Katam R, Chibanguza K, Latinwo LM, and Smith D. 2015. Proteome biomarkers in xylem reveal pierce's disease tolerance in grape. Journal of Proteomics \& Bioinformatics 8:217-224.

Keller A, Nesvizhskii AI, Kolker E, and Aebersold R. 2002. Empirical statistical model to estimate the accuracy of peptide identifications made by MS/MS and database search. Anal Chem 74:5383-5392.

Khersonsky O, and Tawfik DS. 2010. Enzyme promiscuity: a mechanistic and evolutionary perspective. Annu Rev Biochem 79:471-505. 10.1146/annurev-biochem-030409-143718

Kleywegt GJ. 1999. Recognition of spatial motifs in protein structures. J Mol Biol 285:1887-1897. S00222836(98)92393-2 [pii]

10.1006/jmbi.1998.2393

Konc J, and Janezic D. 2010. ProBiS algorithm for detection of structurally similar protein binding sites by local structural alignment. Bioinformatics 26:1160-1168. 10.1093/bioinformatics/btq100

Lin H, Doddapaneni H, Takahashi Y, and Walker MA. 2007. Comparative analysis of ESTs involved in grape responses to Xylella fastidiosa infection. BMC Plant Biol 7:8. 1471-2229-7-8 [pii]

10.1186/1471-2229-7-8

Liu JJ, Sturrock R, and Ekramoddoullah AK. 2010. The superfamily of thaumatin-like proteins: its origin, evolution, and expression towards biological function. Plant Cell Rep 29:419-436. 10.1007/s00299-010-0826-8

Lu S, Faris JD, Sherwood R, and Edwards MC. 2013. Dimerization and protease resistance: new insight into the function of PR-1. J Plant Physiol 170:105-110. S0176-1617(12)00328-8 [pii]

10.1016/j.jplph.2012.08.006

Martinez-Caballero S, Cano-Sanchez P, Mares-Mejia I, Diaz-Sanchez AG, Macias-Rubalcava ML, Hermoso JA, and Rodriguez-Romero A. 2014. Comparative study of two GH19 chitinase-like proteins from Hevea brasiliensis, one exhibiting a novel carbohydrate-binding domain. FEBS $J$ 281:4535-4554. 10.1111/febs. 12962

Mauch F, Mauch-Mani B, and Boller T. 1988. Antifungal Hydrolases in Pea Tissue : II. Inhibition of Fungal Growth by Combinations of Chitinase and beta-1,3-Glucanase. Plant Physiol 88:936-942.

McElrone AJ, Sherald JL, and Forseth IN. 2003. Interactive effects of water stress and xylem-limited bacterial infection on the water relations of a host vine. J Exp Bot 54:419-430.

Metzner R, Schneider HU, Breuer U, Thorpe MR, Schurr U, and Schroeder WH. 2010. Tracing cationic nutrients from xylem into stem tissue of French bean by stable isotope tracers and cryo-secondary ion mass spectrometry. Plant Physiol 152:1030-1043. pp.109.143776 [pii]

10.1104/pp.109.143776

Mi H, Muruganujan A, Casagrande JT, and Thomas PD. 2013. Large-scale gene function analysis with the PANTHER classification system. Nat Protoc 8:1551-1566. nprot.2013.092 [pii]

10.1038/nprot.2013.092

Moy P, Qutob D, Chapman BP, Atkinson I, and Gijzen M. 2004. Patterns of gene expression upon infection of soybean plants by Phytophthora sojae. Mol Plant Microbe Interact 17:1051-1062. 10.1094/MPMI.2004.17.10.1051

Nanjo Y, Nakamura T, and Komatsu S. 2013. Identification of Indicator Proteins Associated with Flooding Injury in Soybean Seedlings Using Label-free Quantitative Proteomics. Journal of Proteome Research 12:47854798. 10.1021/pr4002349 
Nersissian AM, Immoos C, Hill MG, Hart PJ, Williams G, Herrmann RG, and Valentine JS. 1998. Uclacyanins, stellacyanins, and plantacyanins are distinct subfamilies of phytocyanins: plant-specific mononuclear blue copper proteins. Protein Sci 7:1915-1929. 10.1002/pro.5560070907

Nesvizhskii AI, Keller A, Kolker E, and Aebersold R. 2003. A statistical model for identifying proteins by tandem mass spectrometry. Anal Chem 75:4646-4658.

Ng EK, Chong WW, Jin H, Lam EK, Shin VY, Yu J, Poon TC, Ng SS, and Sung JJ. 2009. Differential expression of microRNAs in plasma of patients with colorectal cancer: a potential marker for colorectal cancer screening. Gut 58:1375-1381. gut.2008.167817 [pii]

10.1136/gut.2008.167817

Nicaise V, Roux M, and Zipfel C. 2009. Recent advances in PAMP-triggered immunity against bacteria: pattern recognition receptors watch over and raise the alarm. Plant Physiol 150:1638-1647. pp.109.139709 [pii]

10.1104/pp.109.139709

Niza B, Coletta-Filho HD, Merfa MV, Takita MA, and de Souza AA. 2015. Differential colonization patterns of Xylella fastidiosa infecting citrus genotypes. Plant Pathology 64:1259-1269.

Ohnuma T, Numata T, Osawa T, Mizuhara M, Lampela O, Juffer AH, Skriver K, and Fukamizo T. 2011. A class V chitinase from Arabidopsis thaliana: gene responses, enzymatic properties, and crystallographic analysis. Planta 234:123-137. 10.1007/s00425-011-1390-3

Okushima Y, Koizumi N, Kusano T, and Sano H. 2000. Secreted proteins of tobacco cultured BY2 cells: identification of a new member of pathogenesis-related proteins. Plant Mol Biol 42:479-488.

Petre B, Major I, Rouhier N, and Duplessis S. 2011. Genome-wide analysis of eukaryote thaumatin-like proteins (TLPs) with an emphasis on poplar. BMC Plant Biol 11:33. 1471-2229-11-33 [pii]

10.1186/1471-2229-11-33

Pu Z, Ino Y, Kimura Y, Tago A, Shimizu M, Natsume S, Sano Y, Fujimoto R, Kaneko K, Shea DJ, Fukai E, Fuji S, Hirano H, and Okazaki K. 2016. Changes in the Proteome of Xylem Sap in Brassica oleracea in Response to Fusarium oxysporum Stress. Front Plant Sci 7:31. 10.3389/fpls.2016.00031

Rep M, Dekker HL, Vossen JH, de Boer AD, Houterman PM, Speijer D, Back JW, de Koster CG, and Cornelissen BJ. 2002. Mass spectrometric identification of isoforms of PR proteins in xylem sap of fungus-infected tomato. Plant Physiol 130:904-917. 10.1104/pp.007427

Rice P, Longden I, and Bleasby A. 2000. EMBOSS: the European Molecular Biology Open Software Suite. Trends Genet 16:276-277. S0168-9525(00)02024-2 [pii]

Rodrigues CM, de Souza AA, Takita MA, Kishi LT, and Machado MA. 2013. RNA-Seq analysis of Citrus reticulata in the early stages of Xylella fastidiosa infection reveals auxin-related genes as a defense response. $B M C$ Genomics 14:676. 1471-2164-14-676 [pii]

$10.1186 / 1471-2164-14-676$

Safavi K, Zareie R, and Tabatabaei BES. 2012. Constitutive expression of thaumatin-like protein (TLP-3) in transgenic tobacco plants leads to enhance resistance to Alternaria alternata. Archives of Phytopathology and Plant Protection 45:161-169. 10.1080/03235408.2010.507947

Sanchez-Rangel D, Sanchez-Nieto S, and Plasencia J. 2012. Fumonisin B1, a toxin produced by Fusarium verticillioides, modulates maize beta-1,3-glucanase activities involved in defense response. Planta 235:965-978. 10.1007/s00425-011-1555-0

Sela-Buurlage MB, Ponstein AS, Bres-Vloemans SA, Melchers LS, Van Den Elzen P, and Cornelissen B. 1993. Only Specific Tobacco (Nicotiana tabacum) Chitinases and [beta]-1,3-Glucanases Exhibit Antifungal Activity. Plant Physiol 101:857-863.

Shi X, Bi J, Morse JG, Toscano NC, and Cooksey DA. 2010. Differential expression of genes of Xylella fastidiosa in xylem fluid of citrus and grapevine. FEMS Microbiol Lett 304:82-88. FML1885 [pii]

$10.1111 / \mathrm{j} .1574-6968.2009 .01885 . \mathrm{x}$

Shinshi H, Wenzler H, Neuhaus JM, Felix G, Hofsteenge J, and Meins F. 1988. Evidence for N- and C-terminal processing of a plant defense-related enzyme: Primary structure of tobacco prepro-beta-1,3-glucanase. Proc Natl Acad Sci U S A 85:5541-5545.

Shiu SH, and Bleecker AB. 2001. Receptor-like kinases from Arabidopsis form a monophyletic gene family related to animal receptor kinases. Proc Natl Acad Sci U S A 98:10763-10768. 10.1073/pnas.181141598

181141598 [pii]

Stajich JE, Block D, Boulez K, Brenner SE, Chervitz SA, Dagdigian C, Fuellen G, Gilbert JG, Korf I, Lapp H, Lehvaslaiho H, Matsalla C, Mungall CJ, Osborne BI, Pocock MR, Schattner P, Senger M, Stein LD, Stupka E, Wilkinson MD, and Birney E. 2002. The Bioperl toolkit: Perl modules for the life sciences. Genome Res 12:1611-1618. 10.1101/gr.361602 
Su YC, Xu LP, Xue BT, Wu QB, Guo JL, Wu LG, and Que YX. 2013. Molecular cloning and characterization of two pathogenesis-related beta-1,3-glucanase genes ScGluA1 and ScGluD1 from sugarcane infected by Sporisorium scitamineum. Plant Cell Rep 32:1503-1519. 10.1007/s00299-013-1463-9

Subramanian S, Cho UH, Keyes C, and Yu O. 2009. Distinct changes in soybean xylem sap proteome in response to pathogenic and symbiotic microbe interactions. BMC Plant Biol 9:119. 1471-2229-9-119 [pii]

10.1186/1471-2229-9-119

Sudisha J, Sharathchandra R, Amruthesh K, Kumar A, and Shetty HS. 2012. Pathogenesis related proteins in plant defense response. . Plant Defence: Biological Control: Springer, 379-403.

van Loon LC, Rep M, and Pieterse CM. 2006. Significance of inducible defense-related proteins in infected plants. Annu Rev Phytopathol 44:135-162. 10.1146/annurev.phyto.44.070505.143425

Varghese JN, Hrmova M, and Fincher GB. 1999. Three-dimensional structure of a barley beta-D-glucan exohydrolase, a family 3 glycosyl hydrolase. Structure 7:179-190.

Wallis CM, and Chen J. 2012. Grapevine phenolic compounds in xylem sap and tissues are significantly altered during infection by Xylella fastidiosa. Phytopathology 102:816-826. 10.1094/PHYTO-04-12-0074-R

Wang Z, Gerstein M, and Snyder M. 2009. RNA-Seq: a revolutionary tool for transcriptomics. Nat Rev Genet 10:57-63. $\operatorname{nrg} 2484$ [pii]

$10.1038 / \mathrm{nrg} 2484$

Witzel K, Weidner A, Surabhi GK, Borner A, and Mock HP. 2009. Salt stress-induced alterations in the root proteome of barley genotypes with contrasting response towards salinity. $J$ Exp Bot 60:3545-3557. erp198 [pii]

10.1093/jxb/erp198

Xie YR, Raruang Y, Chen ZY, Brown RL, and Cleveland TE. 2015. ZmGns, a maize class I beta-1,3-glucanase, is induced by biotic stresses and possesses strong antimicrobial activity. $J$ Integr Plant Biol 57:271-283. 10.1111/jipb.12286

Yang L, Lin H, Takahashi Y, Chen F, Walker MA, and Civerolo EL. 2011. Proteomic analysis of grapevine stem in response to Xylella fastidiosa inoculation. Physiological and Molecular Plant Pathology 75:90-99.

Yang Y, He M, Zhu Z, Li S, Xu Y, Zhang C, Singer SD, and Wang Y. 2012. Identification of the dehydrin gene family from grapevine species and analysis of their responsiveness to various forms of abiotic and biotic stress. BMC Plant Biol 12:140. 1471-2229-12-140 [pii]

$10.1186 / 1471-2229-12-140$

Ye Y, and Godzik A. 2004. FATCAT: a web server for flexible structure comparison and structure similarity searching. Nucleic Acids Res 32:W582-585. 10.1093/nar/gkh430

32/suppl_2/W582 [pii]

Yoshida S, Ito M, Nishida I, and Watanabe A. 2001. Isolation and RNA gel blot analysis of genes that could serve as potential molecular markers for leaf senescence in Arabidopsis thaliana. Plant Cell Physiol 42:170-178.

Zhang J, Li W, Xiang T, Liu Z, Laluk K, Ding X, Zou Y, Gao M, Zhang X, Chen S, Mengiste T, Zhang Y, and Zhou JM. 2010. Receptor-like cytoplasmic kinases integrate signaling from multiple plant immune receptors and are targeted by a Pseudomonas syringae effector. Cell Host Microbe 7:290-301. S19313128(10)00104-6 [pii]

10.1016/j.chom.2010.03.007

Zhang W, Yan H, Chen W, Liu J, Jiang C, Jiang H, Zhu S, and Cheng B. 2014. Genome-wide identification and characterization of maize expansin genes expressed in endosperm. Mol Genet Genomics 289:1061-1074. 10.1007/s00438-014-0867-8

Zhang YT, Zhang YL, Chen SX, Yin GH, Yang ZZ, Lee S, Liu CG, Zhao DD, Ma YK, Song FQ, Bennett JW, and Yang FS. 2015a. Proteomics of methyl jasmonate induced defense response in maize leaves against Asian corn borer. BMC Genomics 16:224. 10.1186/s12864-015-1363-1

10.1186/s12864-015-1363-1 [pii]

Zhang Z, Xin W, Wang S, Zhang X, Dai H, Sun R, Frazier T, Zhang B, and Wang Q. 2015b. Xylem sap in cotton contains proteins that contribute to environmental stress response and cell wall development. Funct Integr Genomics 15:17-26. 10.1007/s10142-014-0395-y

Zhu J, Sova P, Xu Q, Dombek KM, Xu EY, Vu H, Tu Z, Brem RB, Bumgarner RE, and Schadt EE. 2012. Stitching together multiple data dimensions reveals interacting metabolomic and transcriptomic networks that modulate cell regulation. PLoS Biol 10:e1001301. 10.1371/journal.pbio.1001301

PBIOLOGY-D-11-03979 [pii] 


\section{1}

The CHURNER workflow.

After differentially expressed proteins are selected and grouped by functional analysis, individual protein sequences are used to retrieve UniProt and PDB identificators. All sequences and structures are compared pairwise, and significant structural alignments are then use to reinforce protein functions that are significantly altered in the experiment. Yellow boxes indicate manual steps.

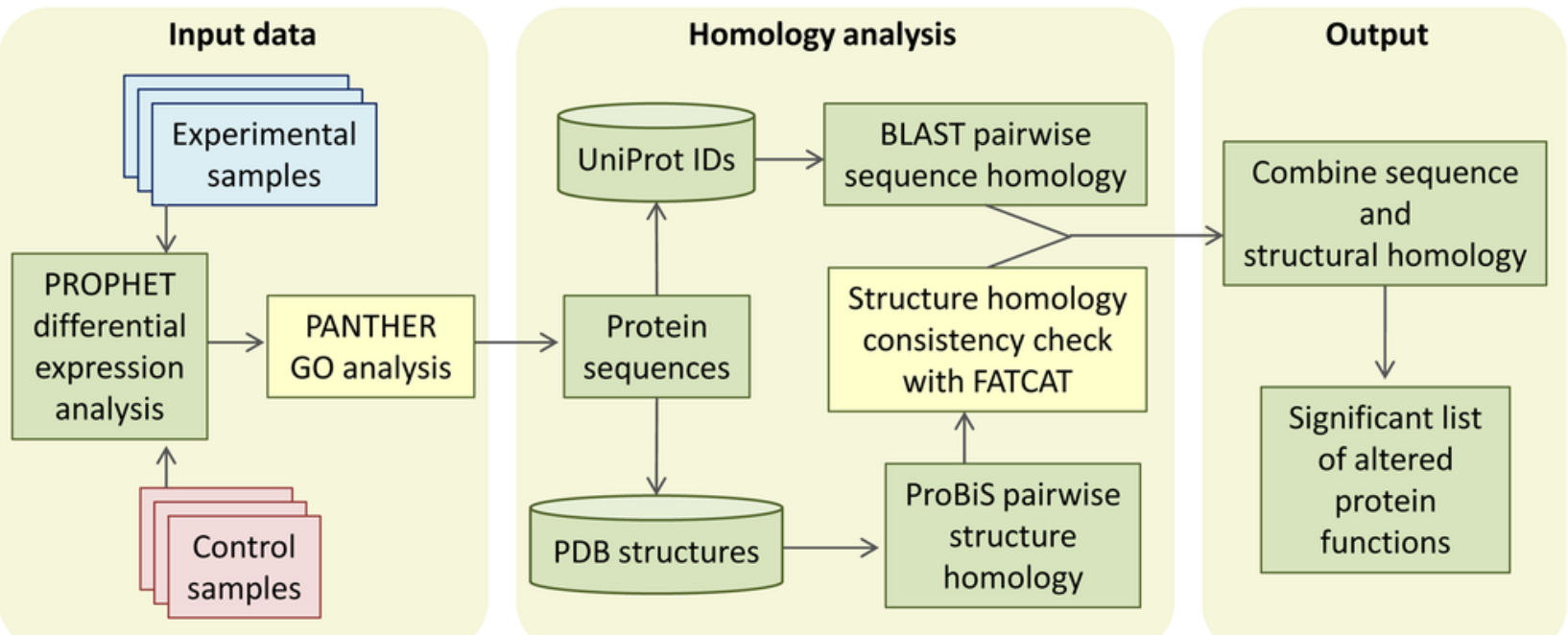




\section{2}

Cell wall thickening of infected grapevines.

Magnetic resonance imaging (1H-MRI) of stems of Xylella fastidiosa (A) infected and (B) noninfected grapevines. Note the brighter contrast (denser material) of secondary xylem and phloem vessels on the infected vine. Both images have the same magnification and scale bar is $5 \mathrm{~mm}$. Images representative of transversal stem cuts obtained near $10 \mathrm{~cm}$ from top central stem. Similar thickening of cell walls were also observed in transversal cuts obtained along the vine until the base near the soil.
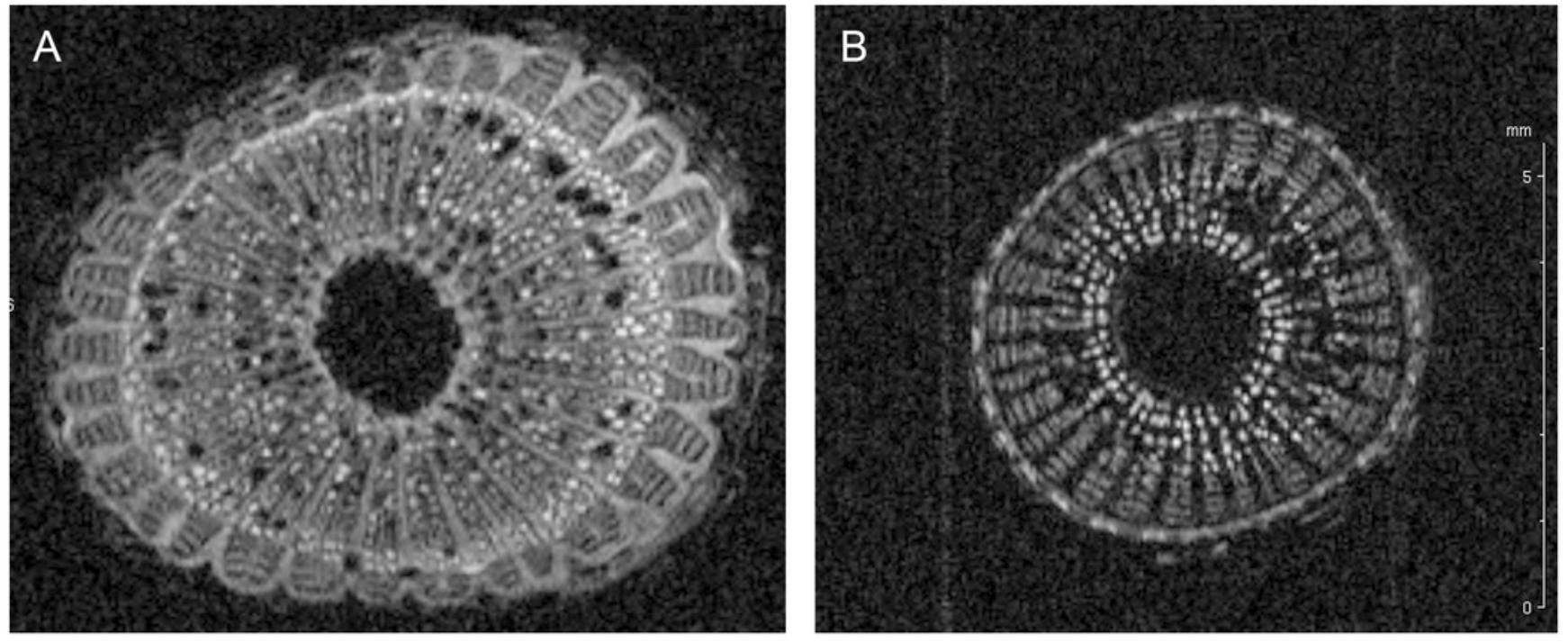


\section{3}

Superimposition of proteins that have significant structural homology.

Structural homology has been detected using ProBiS, and confirmed using FATCAT. (A) Lipid transfer proteins: PDBid: 2RKNA (in magenta) and PDBid: 1FKOA (in cyan). (B) Chitinase GH18 proteins: PDBid: 1HVQA (in magenta) and PDBid: 3AQUA (in cyan). Note, that these proteins have low sequence homology (BLAST E-value $=0.003$ ). (C) Chitinase (PDBid: 3AQUA, in magenta) and $\beta$-D-Glucan Exohydrolase (PDBid: 1EX1A, in cyan). These proteins have low sequence homology $(\mathrm{E}-\mathrm{value}=0.44)$. 

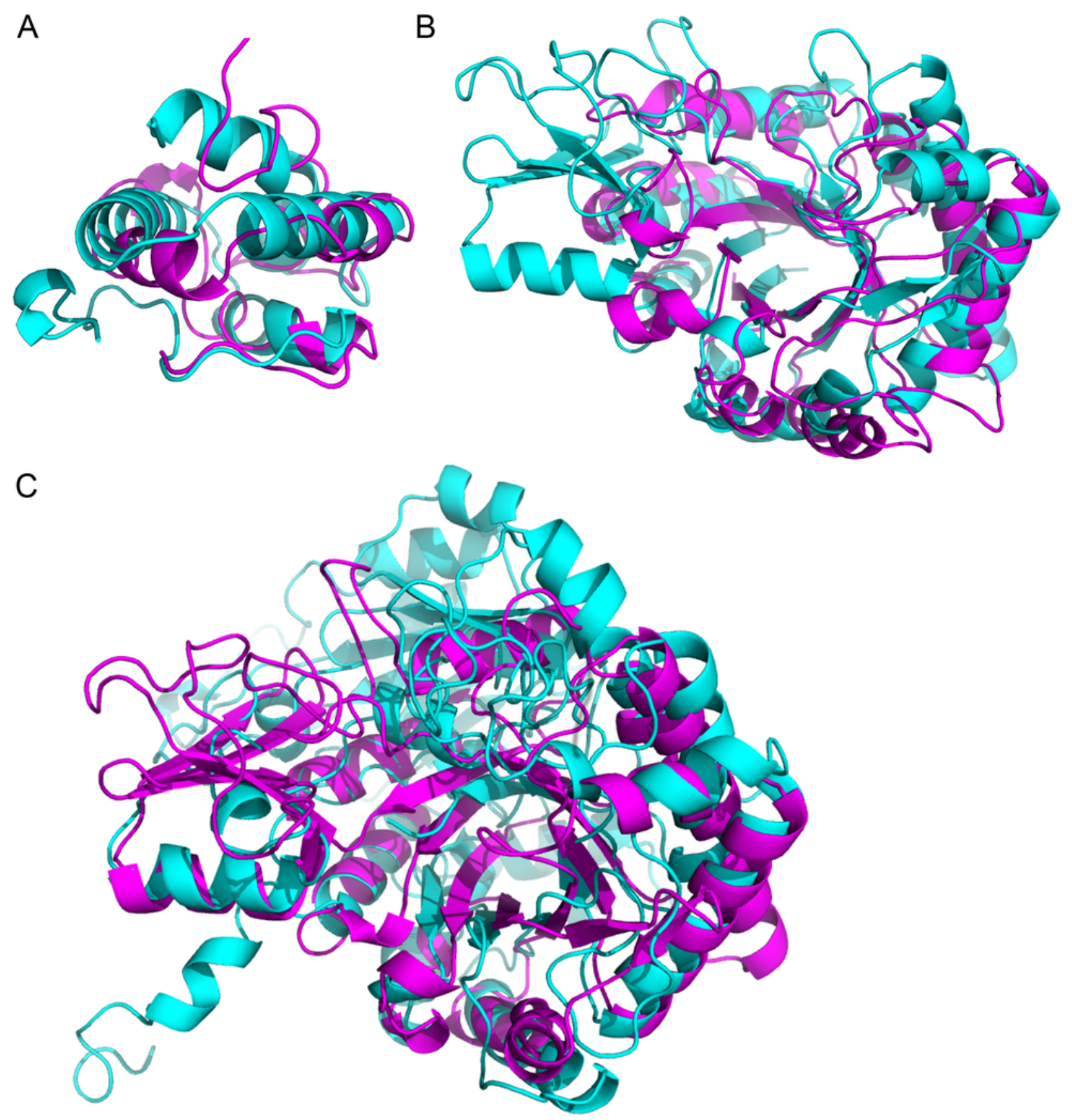
4

Active site residues in the chitinase and $\beta$-D-glucan exohydrolase.

(A) Glu116 (red), Asp114 (green), Trp324 (blue) in chitinase (PDBid:3AQU). (B) Asp285 (red),

Glu491 (green), Trp286 (blue) in $\beta$-D-glucan exohydrolase (PDBid:1EX1A). (C)

Superimposition of the chitinase (in magenta) and $\beta$-D-glucan exohydrolase (in cyan).

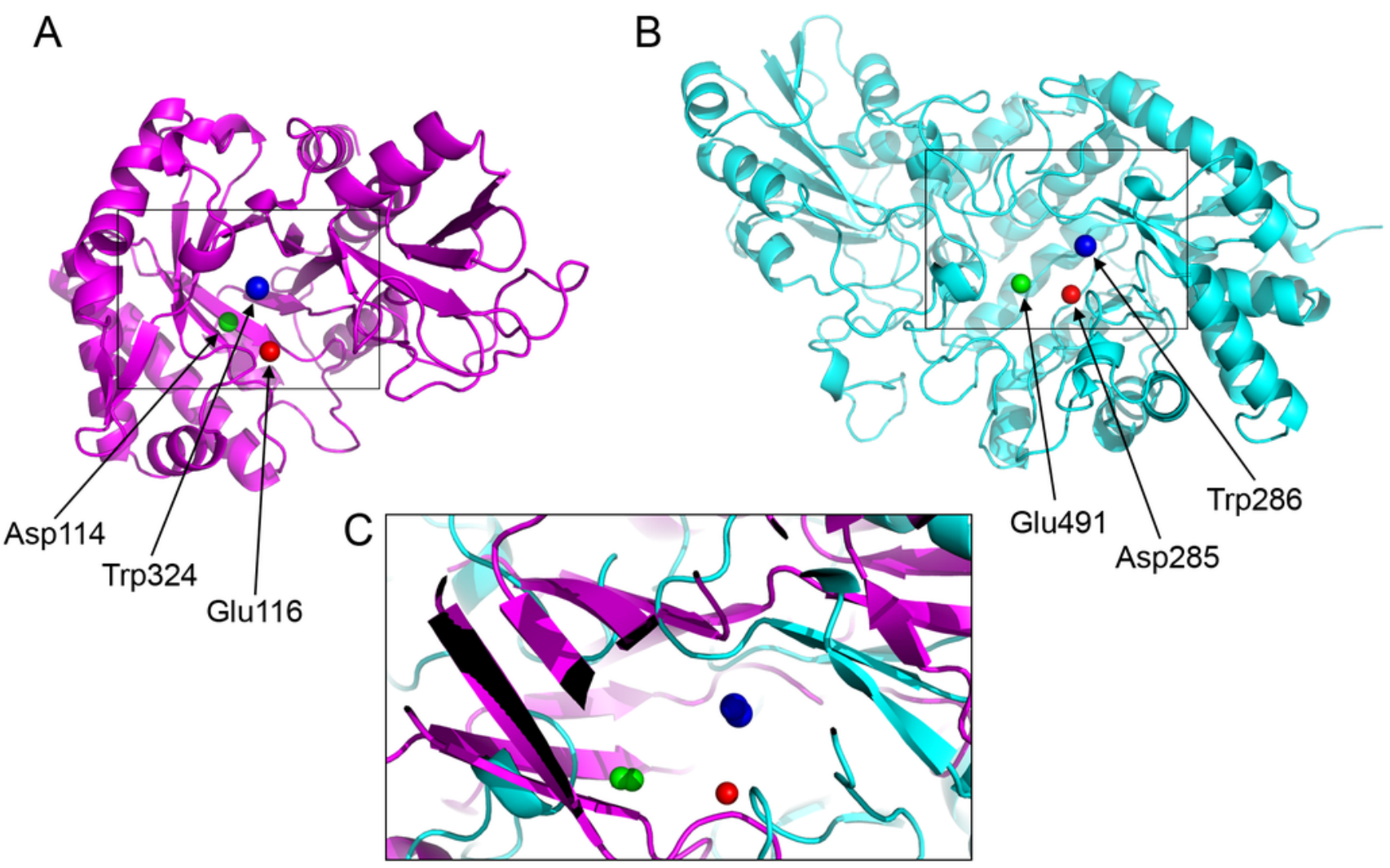




\section{Table 1 (on next page)}

Proteins identified in grapevine xylem sap by LC-MS/MS . 
Table 1. Proteins identified in grapevine xylem sap of Xylella fastidiosa-infected and healthy plants by LC-MS/MS .

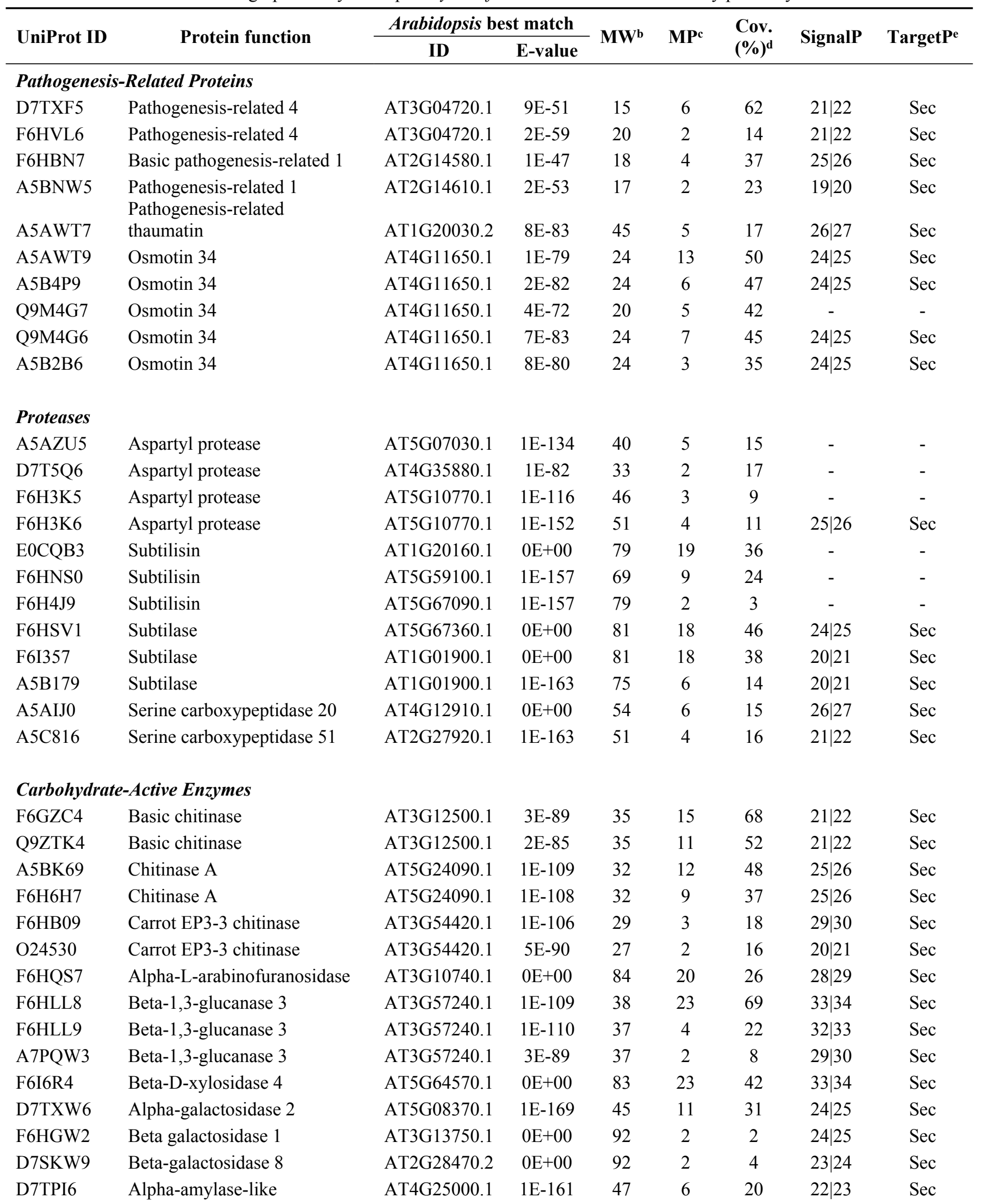




$\begin{array}{lllllllcc}\text { A5C7G0 } & \text { Glucuronidase 3 } & \text { AT5G34940.2 } & 0 \mathrm{E}+00 & 71 & 3 & 8 & 18 \mid 19 & \text { Sec } \\ \text { F6GU88 } & \text { Glycosyl hydrolase } & \text { AT5G12950.1 } & 0 \mathrm{E}+00 & 97 & 5 & 8 & 24 \mid 25 & \text { Sec } \\ \text { A5AZM8 } & \text { Glycosyl hydrolase } & \text { AT2G27500.1 } & 1 \mathrm{E}-132 & 50 & 2 & 5 & - & - \\ \text { F6H158 } & \text { Glycosyl hydrolase } & \text { AT1G58370.1 } & 0 \mathrm{E}+00 & 105 & 5 & 7 & - & - \\ \text { D7SVH6 } & \text { Glycosyl hydrolase } & \text { AT3G26720.1 } & 0 \mathrm{E}+00 & 114 & 2 & 3 & 19 \mid 20 & \text { Sec } \\ \text { D7TQ09 } & \text { O-Glycosyl hydrolases } & \text { AT4G34480.1 } & 1 \mathrm{E}-171 & 52 & 5 & 11 & 24 \mid 25 & \text { Sec } \\ \text { E0CQB9 } & \text { O-Glycosyl hydrolases } & \text { AT4G34480.1 } & 1 \mathrm{E}-178 & 50 & 3 & 12 & 22 \mid 23 & \text { Sec } \\ \text { D7T828 } & \text { O-Glycosyl hydrolases } & \text { AT5G55180.1 } & 0 \mathrm{E}+00 & 50 & 4 & 17 & 20 \mid 21 & \text { Sec } \\ \text { F6HCL5 } & \text { Glycosyl hydrolases } & \text { AT4G19810.1 } & 1 \mathrm{E}-107 & 40 & 5 & 24 & 25 \mid 26 & \text { Sec } \\ \text { D7T548 } & \text { Glycosyl hydrolases } & \text { AT4G19810.1 } & 1 \mathrm{E}-118 & 40 & 5 & 21 & 25 \mid 26 & \text { Sec } \\ \text { A7PZL3 } & \text { Pectin lyase-like } & \text { AT3G61490.3 } & 0 \mathrm{E}+00 & 53 & 2 & 10 & - & - \\ \text { F6HUM8 } & \text { Pectin lyase-like } & \text { AT3G61490.3 } & 0 \mathrm{E}+00 & 52 & 7 & 24 & - & - \\ \text { A5AZD0 } & \text { Callose-binding protein 3 } & \text { AT1G18650.1 } & 3 \mathrm{E}-35 & 20 & 3 & 20 & 19 \mid 20 & \text { Sec } \\ \text { D7SI17 } & \text { Callose-binding protein 3 } & \text { AT1G18650.1 } & \text { 3E-39 } & 21 & 2 & 20 & 19 \mid 20 & \text { Sec } \\ \text { A5C594 } & \text { Expansin-like } & \text { AT4G17030.1 } & \text { 2E-40 } & 23 & 6 & 42 & 24 \mid 25 & \text { Sec }\end{array}$

\section{Receptor-like Kinases (RLKs)}

F6HIL5 Receptor-like kinase-related Leucine-rich repeat (LRR)

D7TPF3 SHV3-like 2
A5AID0 Receptor-like kinase-related
AT3G22060.1 8E-69

AT5G48540.1 2E-74
AT4G06744.1 1E-108
27 45

49
$16 \quad 64$

$$
3
$$

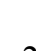

\section{Peroxidases}

$\begin{array}{ll}\text { F6GUF3 } & \text { Peroxidase 2 } \\ \text { F6GUE9 } & \text { Peroxidase } \\ \text { F6HD61 } & \text { Peroxidase } \\ \text { A5BJV9 } & \text { Peroxidase } \\ \text { F6H776 } & \text { Peroxidase } \\ \text { F6HIK4 } & \text { Peroxidase } \\ \text { D7TQI6 } & \text { Peroxidase } \\ \text { F6H3X3 } & \text { Peroxidase } \\ \text { D7SVP1 } & \text { Peroxidase } \\ \text { F6GXY7 } & \text { Peroxidase } \\ \text { D7SR21 } & \text { Peroxidase } \\ \text { F6H0Z1 } & \text { Peroxidase } \\ \text { A5B8V0 } & \text { Peroxidase } \\ \text { F6HH88 } & \text { Peroxidase } \\ \text { F6HSU5 } & \text { Peroxidase }\end{array}$

\section{Others}

E0CQL6

D7TML8

D7SLG6

F6H7X9

A5C9S3

F6I0G4
Basic blue protein-like

Inhibitor / LTP / seed storage

Inhibitor / LTP / seed storage

Inhibitor / LTP / seed storage

Inhibitor / LTP / seed storage

Pectin methylesterase inhibitor

$\begin{array}{ccccccc}\text { AT5G06720.1 } & 1 \mathrm{E}-109 & 36 & 2 & 7 & 23 \mid 24 & \mathrm{Sec} \\ \text { AT5G19890.1 } & 1 \mathrm{E}-104 & 29 & 15 & 65 & - & - \\ \text { AT1G49570.1 } & 1 \mathrm{E}-110 & 36 & 11 & 35 & 25 \mid 26 & \mathrm{Sec} \\ \text { AT5G58390.1 } & 3 \mathrm{E}-77 & 28 & 9 & 49 & - & - \\ \text { AT1G05260.1 } & 8 \mathrm{E}-77 & 74 & 11 & 23 & 21 \mid 22 & \mathrm{Sec} \\ \text { AT1G05260.1 } & 1 \mathrm{E}-135 & 76 & 2 & 3 & 26 \mid 27 & \mathrm{Sec} \\ \text { AT2G37130.1 } & 1 \mathrm{E}-137 & 37 & 7 & 29 & - & - \\ \text { AT5G14130.1 } & 8 \mathrm{E}-98 & 34 & 5 & 22 & 34 \mid 35 & - \\ \text { AT5G14130.1 } & 2 \mathrm{E}-20 & 10 & 2 & 43 & - & - \\ \text { AT5G05340.1 } & 7 \mathrm{E}-96 & 28 & 2 & 13 & - & - \\ \text { AT5G05340.1 } & 3 \mathrm{E}-98 & 28 & 3 & 19 & - & - \\ \text { AT5G05340.1 } & 1 \mathrm{E}-113 & 34 & 2 & 13 & 22 \mid 23 & \mathrm{Sec} \\ \text { AT2G41480.1 } & 6 \mathrm{E}-91 & 30 & 2 & 12 & - & - \\ \text { AT2G41480.1 } & 1 \mathrm{E}-120 & 70 & 2 & 7 & 24 \mid 25 & \mathrm{Sec} \\ \text { AT5G67400.1 } & 1 \mathrm{E}-138 & 36 & 3 & 17 & 27 \mid 28 & \mathrm{Sec}\end{array}$

$\begin{array}{lllll}\text { AT2G02850.1 } & 8 \mathrm{E}-38 & 19 & 8 & 49\end{array}$

$\begin{array}{lllll}\text { AT3G53980.2 } & 2 \mathrm{E}-33 & 12 & 11 & 67\end{array}$

$\begin{array}{lllll}\text { AT2G44290.1 } & 1 \mathrm{E}-35 & 19 & 3 & 26\end{array}$

$\begin{array}{lllll}\text { AT4G33550.2 } & 1 \mathrm{E}-07 & 12 & 3 & 39\end{array}$

AT4G33550.2 4E-05

AT5G09760.1 $0 \mathrm{E}+00$

$\begin{array}{lll}12 & 2 & 25\end{array}$

61

\section{$24 \mid 25$}

$25 \mid 26$

$28 \mid 29$
$\mathrm{Sec}$

$\mathrm{Sec}$

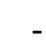




\begin{tabular}{llccccccc} 
A5BS35 & Basic seretory protein & AT2G15220.1 & $1 \mathrm{E}-83$ & 25 & 10 & 53 & $23 \mid 24$ & Sec \\
F6HS61 & Glycine-rich protein & AT4G30460.1 & $7 \mathrm{E}-03$ & 13 & 7 & 67 & $22 \mid 23$ & $\mathrm{Sec}$ \\
A5AIZ1 & Glycine-rich protein & AT4G30460.1 & $3 \mathrm{E}-03$ & 13 & 4 & 67 & $22 \mid 23$ & $\mathrm{Sec}$ \\
D7TY88 & Protease inhibitor & AT1G17860.1 & $6 \mathrm{E}-58$ & 23 & 5 & 23 & $27 \mid 28$ & $\mathrm{Sec}$ \\
D7T293 & Cupredoxin & AT4G12420.2 & $0 \mathrm{E}+00$ & 66 & 2 & 5 & $23 \mid 24$ & $\mathrm{Sec}$ \\
A5BMY7 & Cupredoxin & AT1G72230.1 & $7 \mathrm{E}-23$ & 19 & 2 & 18 & $22 \mid 23$ & $\mathrm{Sec}$ \\
D7UBD5 & Cupredoxin & AT3G27200.1 & $4 \mathrm{E}-40$ & 18 & 4 & 41 & $23 \mid 24$ & $\mathrm{Sec}$ \\
A5BZS1 & FAD-binding Berberine & AT4G20840.1 & $1 \mathrm{E}-179$ & 59 & 5 & 10 & $30 \mid 31$ & $\mathrm{Sec}$ \\
A5B2E1 & Cystatin / Monellin & AT5G47550.1 & $2 \mathrm{E}-29$ & 13 & 2 & 15 & $24 \mid 25$ & $\mathrm{Sec}$ \\
A5BH21 & PLC-like phosphodiesterase & AT1G66970.1 & $0 \mathrm{E}+00$ & 70 & 3 & 5 & $21 \mid 22$ & $\mathrm{Sec}$ \\
D7SVW5 & PI-PLC-like & AT4G36945.1 & $1 \mathrm{E}-143$ & 45 & 2 & 9 & $27 \mid 28$ & $\mathrm{Sec}$ \\
A5BB66 & Fasciclin-like & AT3G60900.1 & $1 \mathrm{E}-117$ & 43 & 3 & 15 & $20 \mid 21$ & - \\
A5B7N6 & Fasciclin-like & AT4G12730.1 & $1 \mathrm{E}-115$ & 44 & 2 & 8 & $26 \mid 27$ & $\mathrm{Sec}$ \\
D7SXH0 & Lamin-like & AT5G15350.1 & $3 \mathrm{E}-37$ & 18 & 2 & 15 & - & - \\
A5AIY9 & Unknown protein & - & - & 15 & 4 & 59 & $23 \mid 24$ & Sec \\
\hline
\end{tabular}

${ }^{\mathrm{a}} \mathrm{A}$ total of 91 proteins with at least two peptides sequenced per protein were identified and are displayed grouped by functional category. ${ }^{\mathrm{b}}$ Predicted molecular weight of proteins, in $\mathrm{kDa} .{ }^{\mathrm{c}}$ Matched peptides. ${ }^{\mathrm{d}}$ Percentage of coverage. ${ }^{\mathrm{e}}$ TargetP output: $\mathrm{Sec}=$ secreted protein, - = undefined. 


\section{Table 2(on next page)}

Differentially expressed proteins and their sequence and structure similarities with reference proteins. 
Table 2. Differentially expressed proteins and their sequence and structure similarities with reference proteins.

\begin{tabular}{|c|c|c|c|c|c|}
\hline \multirow{2}{*}{$\begin{array}{l}\text { UniProt } \\
\text { ID }\end{array}$} & \multirow[b]{2}{*}{ Protein function } & \multicolumn{3}{|c|}{ GenBank / Protein Data Base } & \multirow[t]{2}{*}{ Exp. $^{\mathrm{a}}$} \\
\hline & & ID & Score & E-value & \\
\hline F6HLL8 & $\beta$ 1-3 glucanase & NP 001268153.1 / 4HPG & $696 / 423$ & $0 \mathrm{e}+00 / 1 \mathrm{e}-147$ & $\mathrm{Up}$ \\
\hline A5BK69 & Class III chitinase & ACH54087.1 / 1HVQ & $592 / 435$ & $0 \mathrm{e}+00 / 1 \mathrm{e}-153$ & $\mathrm{Up}$ \\
\hline D7T548 & Chitotriosidase-1 & XP.1002270368.1 / 3AQU & $743 / 452$ & $0 \mathrm{e}+00 / 5 \mathrm{e}-158$ & $\mathrm{Up}$ \\
\hline F6HBN7 & Pathogenesis-related & XP 002274275 / 1CFE & $334 / 184$ & $1 e-114 / 3 e-59$ & $\mathrm{Up}$ \\
\hline A5BNW5 & Pathogenesis-related & XP 002273788.2 / 1CFE & $333 / 186$ & $7 \mathrm{e}-114 / 4 \mathrm{e}-60$ & $\mathrm{Up}$ \\
\hline D7TML8 & Lipid-transfer protein & XP 002281554.1/2RKN & $239 / 36.2$ & $9 e-79 / 7 e-04$ & $\mathrm{Up}$ \\
\hline A5C594 & $\begin{array}{l}\text { Expansin-like } \\
\text { Blue copper protein- }\end{array}$ & XP 002270175.2 / 2HCZ & $374 / 89$ & $2 \mathrm{e}-128 / 5 \mathrm{e}-21$ & $\mathrm{Up}$ \\
\hline E0CQL6 & like & XP 002266573.1 / 2CBP & $268 / 158$ & $4 e-89 / 3 e-49$ & Up \\
\hline F6GZC4 & Chitinase & CAC14015.1 / 4DWX & $660 / 385$ & $0 \mathrm{e}+00 / 7 \mathrm{e}-134$ & Down \\
\hline A5AWT7 & Thaumatin-like $1 \mathrm{~b}$ & XP 002274137.1 / 3ZS3 & $518 / 253$ & $1 e-180 / 3 e-81$ & Down \\
\hline F6I6R4 & $\beta$-xylosidase & XP 002264183.2 / 1EX1 & $1605 / 154$ & $0 \mathrm{e}+00 / 2 \mathrm{e}-39$ & Down \\
\hline D7SLG6 & $\begin{array}{l}\text { YLS3-like, Lipid- } \\
\text { transfer protein }\end{array}$ & XP $002285691.1 / 1 \mathrm{FK} 0$ & $355 / 33.9$ & $3 e-122 / 1.7 e-02$ & Down \\
\hline
\end{tabular}

\footnotetext{
${ }^{a}$ Variation of protein level detected in sap from infected grapevine compared to uninfected control.
} 


\section{Table 3 (on next page)}

Pairwise BLAST ${ }^{\mathrm{a}}$ results of example proteins analyzed with CHURNER. 
Table 3. Pairwise BLAST ${ }^{\mathrm{a}}$ results of example proteins analyzed with CHURNER.

\begin{tabular}{ccccc} 
UID $^{\mathbf{b}}$ \#1 & UID \#2 & Identity $^{\mathbf{c}}$ & E-value & Protein function \\
\hline F6HBN7 & A5BNW5 & $120 / 136$ & $8 \mathrm{e}-90$ & Pathogenesis-related proteins (PR-1) \\
D7TML8 & D7SLG6 & $20 / 78$ & $9 \mathrm{e}-08$ & Lipid transfer proteins \\
A5BK69 & A5C594 & $30 / 181$ & $1.6 \mathrm{e}-2$ & Chitinase or expansin (?) \\
F6HBN7 & A5BK69 & $16 / 133$ & 2.4 & PR-1 or Chitinase (?) \\
A5BK69 & D7T548 & $36 / 272$ & $2 \mathrm{e}-3$ & Chitinases GH18 \\
\hline
\end{tabular}

${ }^{a}$ Sequences aligned with bl2seq from NCBI. ${ }^{b}$ UniProt identificator. ${ }^{c}$ Total number of 3 identical amino acid residues considering the best alignment between the two proteins. 
Table 4(on next page)

Pairwise superimposition of the PDB structures using ProBis. 
Table 4. Pairwise superimposition of the PDB structures using ProBiS.

\begin{tabular}{ccccc}
\hline PDBid / UID $^{\mathbf{a}} \mathbf{1}$ & PDBid / UID \#2 & PZ $^{\mathbf{b}}$ & Protein function & FCTSIG \\
\hline 2RKN / D7TML8 & 1FK0 / D7SLG6 & 2.4 & Lipid transfer proteins & Yes \\
1HVQ / A5BK69 & 3AQU / D7T548 & 2 & Chitinases GH18 & Yes \\
3AQU / D7T548 & 1EX1 / F6I6R4 & 1.6 & Chitinase and $\beta$-D-Glucan Exohydrolase & Yes \\
1HVQ / A5BK69 & 1EX1 / F6I6R4 & 1.3 & Chitinase and $\beta$-D-Glucan Exohydrolase & No \\
\hline
\end{tabular}

${ }^{a}$ UID: UniProt identificator. ${ }^{b}$ The results are sorted based on the ProBiS ZScore (PZ). Significance of structural alignment was verified using FATCAT (FCTSIG). Although the two chitinases have no sequence homology, their structural features are conserved. Similarly, we see signifiant structural similarity between a chitinase (UID: D7T548) and a $\beta$-D-Glucan Exohydrolase (UID: F6I6R4). 
Table 5 (on next page)

Potential and spatial congruence of the active site residues in proteins chitinase and $\beta$ D-glucan exohydrolase detected using CLASP. 
Table 5. Potential and spatial congruence of the active site residues in proteins chitinase and $\beta$ D-glucan exohydrolase detected using CLASP.

\begin{tabular}{llllcc}
\hline PDB* & Active site atoms (a,b,c) & & ab & ac & bc \\
\hline 1EX1A & ASP285 OD1,GLU491 OE1,TRP286 CZ2 & D & 6.4 & 8.4 & 9.3 \\
& & PD & -24.1 & -273.2 & -249.1 \\
\hline \multirow{2}{*}{ 3AQU } & GLU116 OE1,ASP114 OD1,TRP324 CZ2 & D & 7.1 & 7.9 & 9.5 \\
& & PD & 49.8 & -296.8 & -346.7 \\
\hline
\end{tabular}

* Chitinase: 1EX1A, $\beta$-D-glucan exohydrolase: 3AQU. The ability of CLASP to select stereochemically equivalent residues (Asp and Glu, both negatively charged residues) is critical to find the homologous active site. $\mathrm{D}=$ Pairwise distance in $\AA$. PD = Pairwise potential difference. See Methods section for units of potential. 